\title{
THE ADAPTIVE SIGNIFICANCE OF DORSAL SPINE VARIATION IN THE FOURSPINE STICKLEBACK, APELTES QUADRACUS. IV. PHENOTYPIC COVARIATION WITH CLOSELY RELATED SPECIES
}

\author{
D. M. BLOUW* AND D. W. HAGEN \\ Department of Biology, University of New Brunswick, Fredericton, New Brunswick, Canada \\ E3B $6 E 1$
}

Received 2.xii.83

\section{SUMMARY}

\begin{abstract}
The fourspine stickleback (Apeltes quadracus) and ninespine stickleback (Pungitius pungitius) have similar ecologies, they often coexist, and they share parallel polymorphisms for the number of dorsal spines. Spine number is positively correlated between them for 86 sites in eastern Canada. Dorsal spine length is positively correlated with spine number within each species, and spine length is positively correlated between them. Spine length for both species is also positively correlated with the presence of predatory fishes and negatively correlated with vegetation cover. Finally, spine number for both Apeltes and Pungitius is lower where they coexist with a new species of stickleback (Gasterosteus sp.) which is found only in environments where predation risk is low. These patterns of covariation within and between species are evidence for natural selection, and they suggest that predators are a selective agent favouring the higher-spined morphs. We discuss these results with respect to the idea that geographic variation in Pungitius reflects historical processes of isolation and differentiation during the Pleistocene era.
\end{abstract}

\section{INTRODUCTION}

A powerful method for detecting the action of natural selection is to search for covariation among homologous polymorphic traits in closely related and ecologically similar species where they coexist (Clarke, 1975; Koehn and Mitton, 1972; Turner 1977). Our research is aimed at identifying the adaptive significance of a polymorphism for the number of dorsal spines in Apeltes quadracus, the fourspine stickleback (Blouw, 1982; Blouw and Hagen, 1981, 1984a, b, $c$; Hagen and Blouw, 1983). As one of several approaches to this problem, we investigate covariation between the phenotypes of Apeltes and those of Pungitius pungitius, the ninespine stickleback, which shares with Apeltes a polymorphism for the number of dorsal spines. We also investigate covariation between these species and the distribution of a new species of stickleback in Nova Scotia, Canada (Hagen, Blouw and Armstrong, in preparation).

Spine number in Apeltes is highly heritable $\left(\mathrm{h}^{2} \approx 0.61\right.$; Hagen and Blouw, 1983). The dorsal spines (fig. 1) vary in number from one to seven, but these extremes are very rare. A geographic survey of 570 sites in the Maritime Provinces of Canada (Blouw and Hagen, 1984a) shows that nearly all populations are polymorphic. The four- and five-spined morphs are the

* Present address: Department of Biology, St. Francis Xavier University, Antigonish, Nova Scotia, Canada B2G 1 C0 

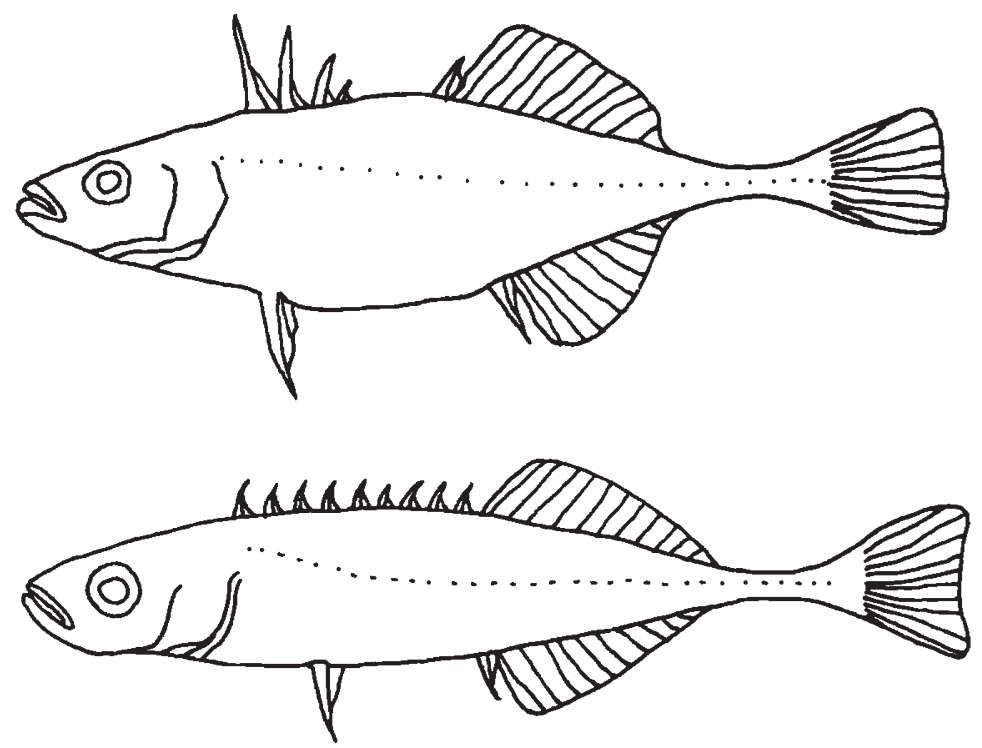

FIG. 1. Lateral views of Apeltes quadracus (above) and Pungitius pungitius (below). Dorsal spine number is polymorphic in both species; shown are the five-spined morph of Apeltes and the nine-spined morph of Pungitius.

most common, with the three- and six-spined less common and rare. Morph frequencies are highly differentiated geographically, with areas of relatively constant frequencies, gentle clines, steep clines, and remarkably abrupt changes we call "intrusions", where frequencies at some sites differ greatly from those at a larger number of surrounding sites (Blouw and Hagen, $1984 a$ ). One of these intrusions, at Louisbourg Harbour, Nova Scotia, is of particular interest with respect to the covariation between Apeltes and Pungitius (see below).

The geographic variation in spine number in Apeltes is correlated with environmental differences among sites (Blouw and Hagen, 1984b). The correlations suggest that predatory fishes act as selective agents favouring the higher-spined morphs. Indeed, populations with higher mean spine number also have longer spines and larger mean body size than populations with fewer spines (Blouw and Hagen, 1984c). Laboratory and field experiments with predators (four fish and one bird species) show that the spine morphs are differentially susceptible to predation. However the higherspined morphs are not always favoured, and vegetation plays a modifying role (Blouw and Hagen, 1984c). Thus the relationship between spine number and predation is complex.

The dorsal spines of Pungitius (fig. 1) are shorter than those of Apeltes, they are more uniform in length and more numerous, but as in Apeltes, they are set at acute angles to the verticle body axis. The two species are similar in size, prefer vegetated areas, nest in vegetation, are cryptically coloured with similar tones outside the breeding season, the breeding colours of males emphasize the pelvic spines, the breeding seasons overlap, they often reside in the same places outside the breeding season, and the diets are similar (Wootton, 1976; Worgan and Fitzgerald, 1981). 


\section{Materials AND MEthods}

We collected Pungitius with Apeltes at 86 sites. Sampling and scoring methods for Pungitius are as described for Apeltes (Blouw and Hagen, 1981, $1984 c$ ) except that the longest of the first three dorsal spines was measured for length. Dorsal spines in Pungitius vary from 6 to 13, but only the eightto eleven-spined morphs are common. We examined homogeneity of morph frequencies between the sexes and among adults and juveniles; the results (table 1) show that, as in Apeltes (Blouw and Hagen, 1981), morph frequencies are homogeneous for both variables. The sexes and size classes are therefore pooled to estimate morph frequencies at each site.

\section{RESUlts}

\section{(i) Covariation with Pungitius}

Sampling sites and scores for Apeltes and Pungitius are shown in table 2. The samples are from the entire area of our detailed geographic survey (Blouw and Hagen 1984a), and they cover the full range of dorsal spine variation in Apeltes. Spine number in Pungitius, like that of Apeltes, is highly differentiated among sites (table 2). Thus there is ample geographic variation to test for covariation between them.

The correlation between dorsal spine number in Apeltes and Pungitius (fig. 2) is positive and highly significant $(\mathrm{r}=0.45 ; \mathrm{P}<0.001)$. However, the covariation breaks down at two sites (lower right corner, fig. 2). These are at the intrusion for high spine number of Apeltes at Louisbourg Harbour (sites 324 and 325, table 2). Thus the agent responsible for high spine number in Apeltes at Louisbourg Harbour does not produce a parallel response in Pungitius, suggesting that some unique process occurs there.

Earlier studies suggest that predators are selective agents on the spines of Apeltes (Blouw and Hagen, 1984b, c). If the covariation between Apeltes and Pungitius is due to selective predation, we predict that spine length in Pungitius should be greater where spine number is higher, as is found in Apeltes (Blouw and Hagen, 1984c). We scored 43 samples of Pungitius for spine length (table 2). To control for size differences among populations, we standardised spine length to a common body length of $33 \mathrm{~mm}$ for each site using intrapopulation regression equations of spine length on body length. Spine length and spine number are positively correlated among populations $(r=0.41 ; P<0.01)$. The 43 samples used to score spine length for Pungitius were also used to score spine length for Apcltes (table 2) and, as expected, standardised spine length is positively correlated between them ( $r=0.64, \mathrm{P}<0.001)$. Thus Apeltes and Pungitius vary in parallel for both spine number and spine length, and the pattern is consistent with the hypothesis that predators are selective agents favouring the higher-spined morphs.

It is clearly of interest to see if spine length is in fact greater at sites where predators are present. Samples were scored as having predators using the methods of Blouw and Hagen (1984b). Predators were shown to be present at only 7 of the 43 sites during our survey (however this does not necessarily mean that the other 36 sites do not have predators-see Blouw and Hagen, $1984 b$ for limitations of predator sampling). Because of these 


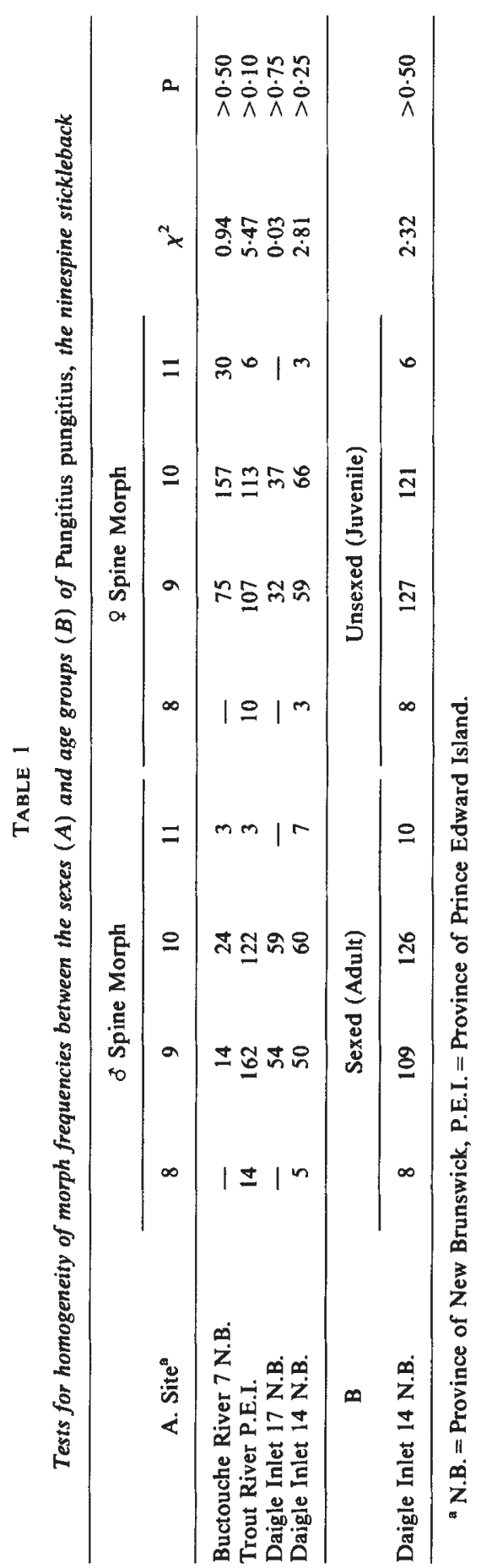




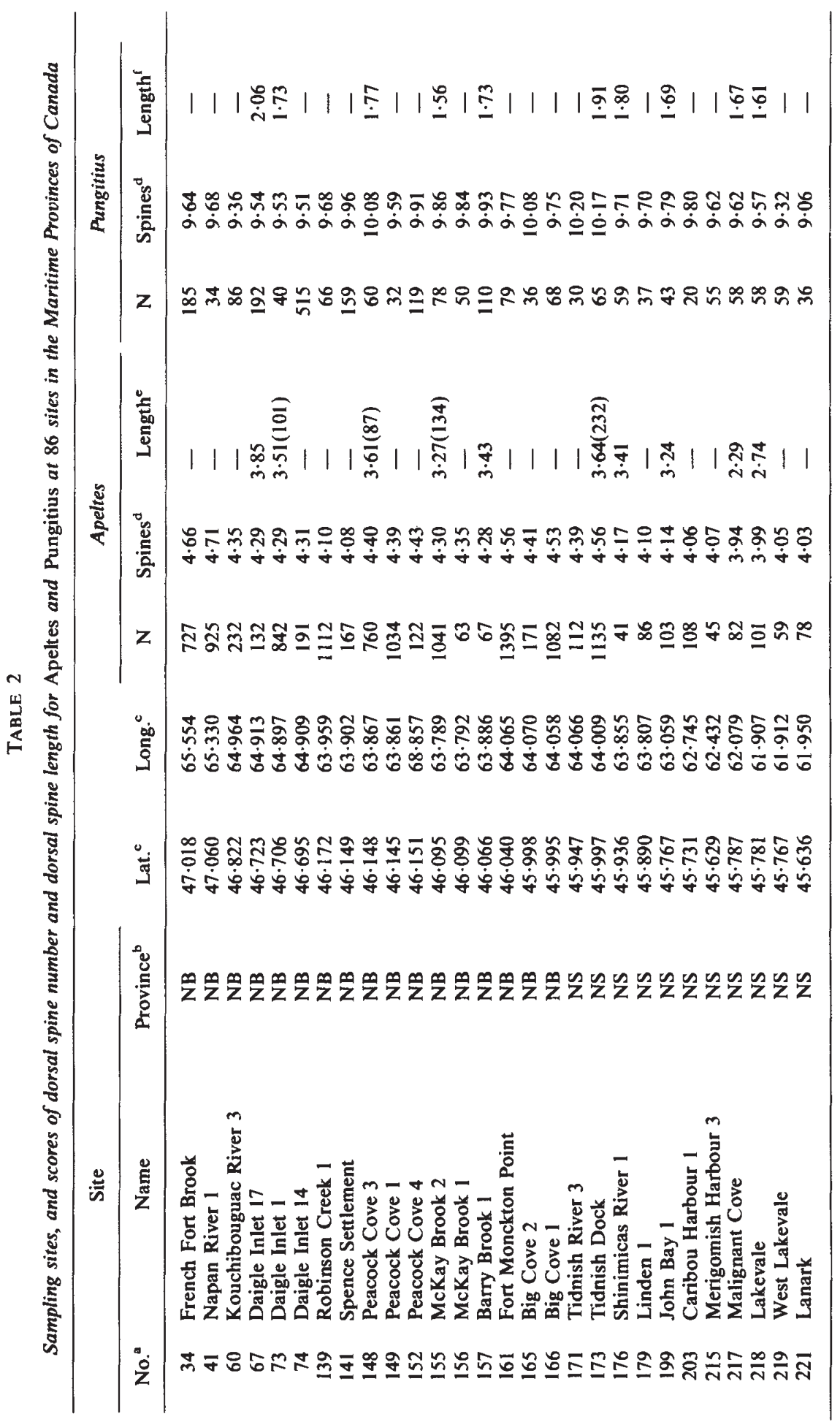




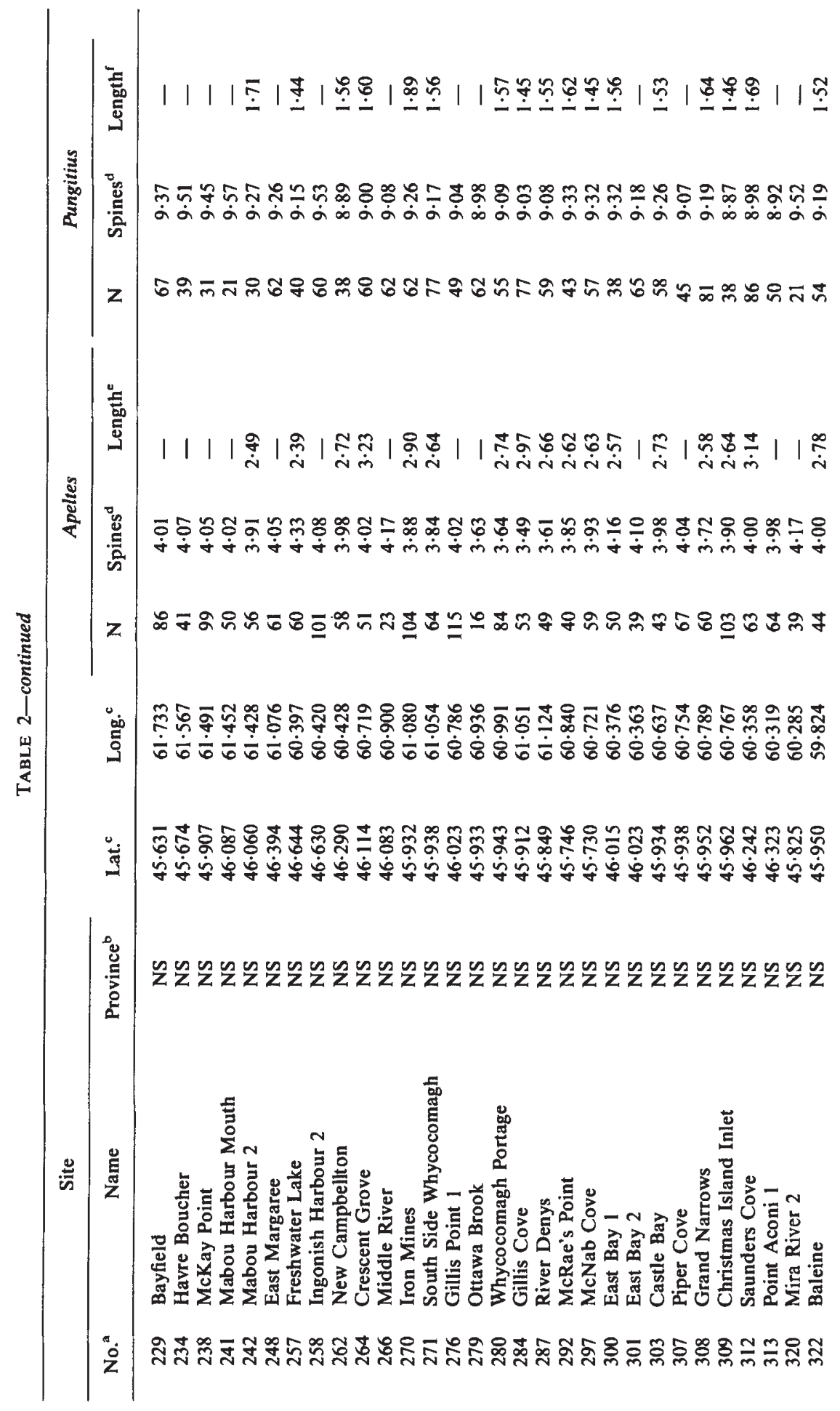




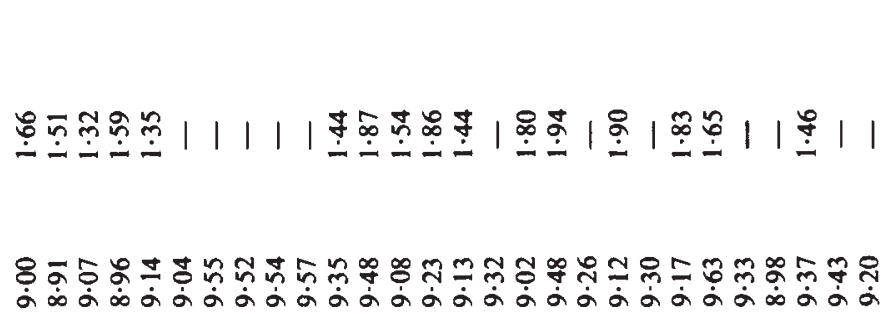

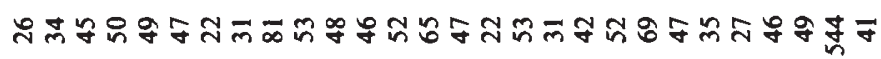

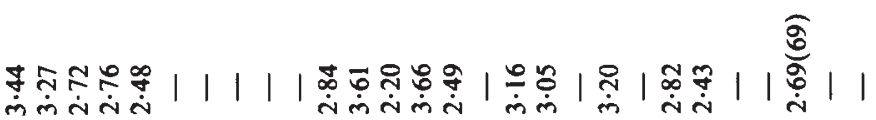

ڤீळ

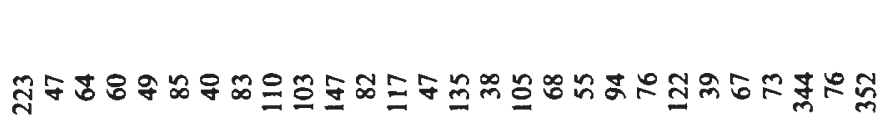

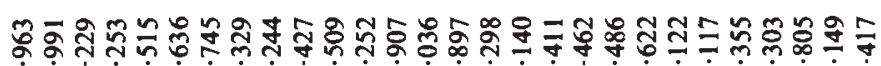

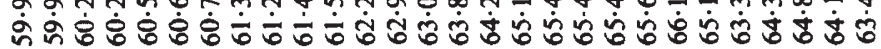

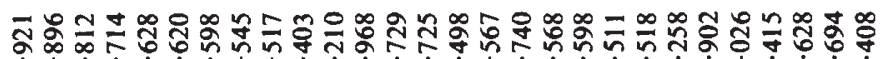

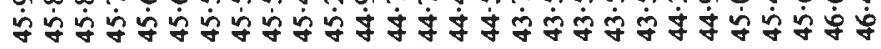

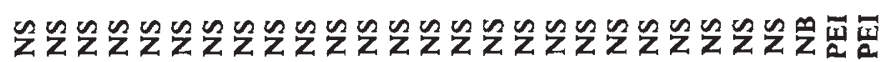

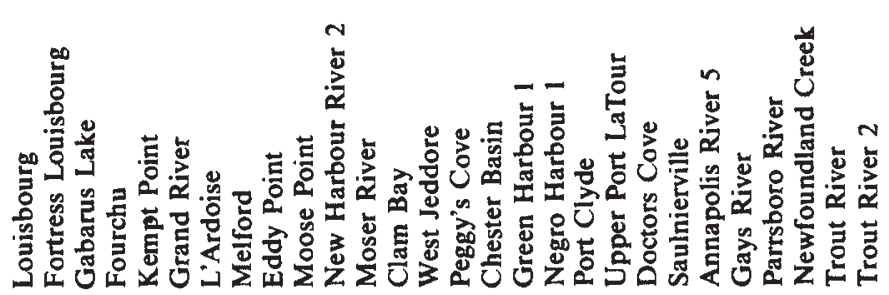

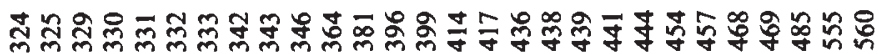$$
\text { 官 }
$$

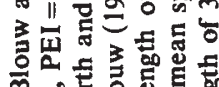

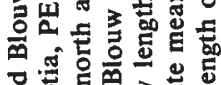

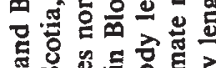

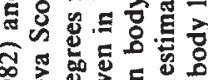

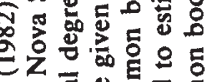

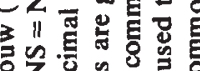




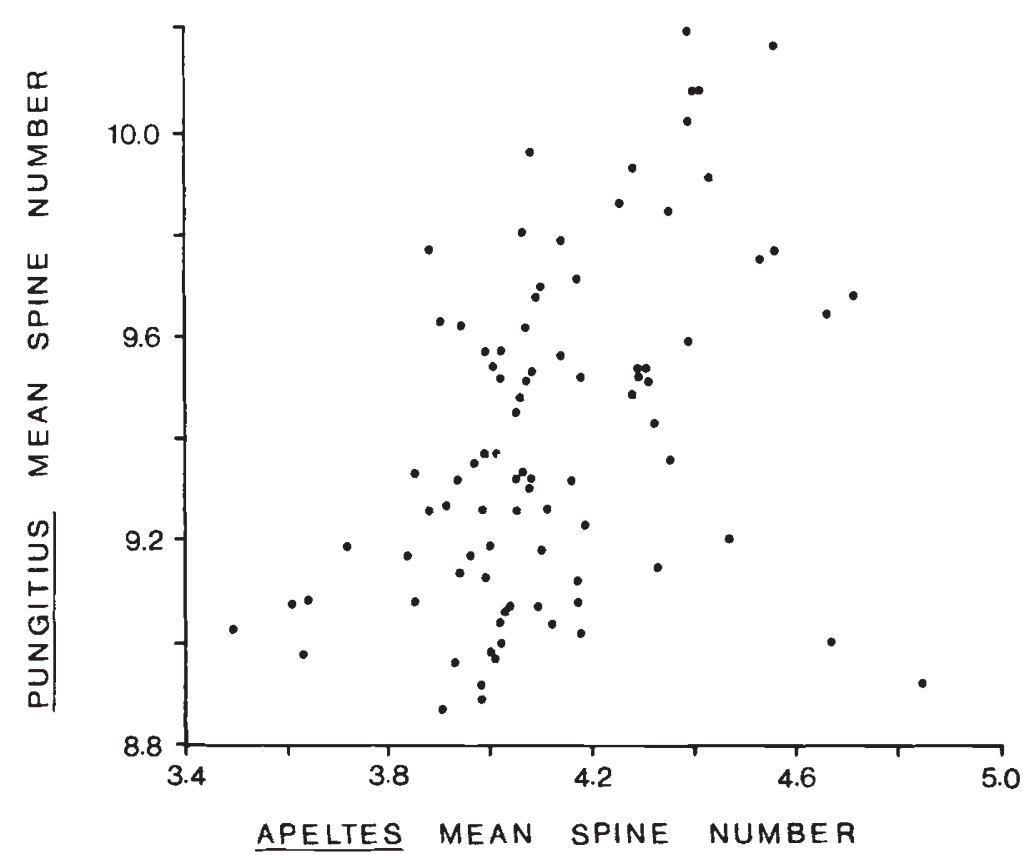

FIG. 2. The relationship between mean spine number in Apeltes and mean spine number in Pungitius. The two points at bottom right are from sites at Louisbourg Harbour, Nova Scotia.

highly unequal sample sizes the median test was applied, and the contingency tables (table 3) were analysed by Fisher's exact test (Zar, 1974). The median test is only about 64 per cent as powerful as analysis of variance so evaluation of the null hypothesis of equal spine lengths is conservative. Yet the null hypothesis is strongly rejected for both Apeltes and Pungitius (table 3); dorsal spines are longer where predators occur.

Previous studies also show that spine number in Apeltes is higher at sites with aquatic grasses and lower at sites with filamentous algae (Blouw and Hagen, 1984b). To see if there is also a relationship between vegetation and spine length, sites were scored as having abundant filamentous algae or abundant grasses. Some sites have roughly equal proportions, and others have neither in abundance but these were excluded because there were too few sites in either category to provide meaningful comparison. The results (table 3) show that spine length is greater for both species in the environments with grasses. Dense algae probably give better cover from predators than do grasses (Blouw and Hagen, 1984b), and predators are less abundant at sites with dense algae in any event (Blouw, 1982), so the differences in spine length are as expected if predation is influential.

\section{(ii) Covariation with a new species of stickleback}

Gasterosteus aculeatus (threespine stickleback) males usually develop red throats, blue irises, and cryptic bodies during the breeding season, but there is variation both within and among populations for breeding colours (Gilbertson, 1980; Hagen and Moodie, 1979; Hagen et al., 1980; Moodie, 
TABLE 3

Median tests for differences in standardised spine length of Apeltes and Pungitius among environments with and without predators $(A)$, and with different types of vegetation $(B)$

\begin{tabular}{|c|c|c|c|c|c|c|}
\hline \multirow[b]{2}{*}{ A. Spine Length } & \multicolumn{2}{|c|}{ Predators present } & \multicolumn{2}{|c|}{ Predators absent } & \multirow[b]{2}{*}{$\chi^{2}(1)^{\mathrm{a}}$} & \multirow[b]{2}{*}{$\mathbf{P}$} \\
\hline & $<$ Median & $>$ Median & $<$ Median & $>$ Median & & \\
\hline Apeltes & 1 & 6 & 20 & 15 & - & $<0.01$ \\
\hline \multirow[t]{2}{*}{ Pungitius } & 1 & 6 & 20 & 15 & - & $<0.01$ \\
\hline & \multicolumn{2}{|c|}{$\begin{array}{l}\text { Abundant } \\
\text { grasses }\end{array}$} & \multicolumn{2}{|c|}{$\begin{array}{c}\text { Abundant } \\
\text { filamentous algae }\end{array}$} & & \\
\hline B. Spine Length & $<$ Median & $>$ Median & $<$ Median & $>$ Median & & \\
\hline Apeltes & 3 & 10 & 13 & 6 & $4 \cdot 66$ & $<0.05$ \\
\hline Pungitius & 2 & 11 & 14 & 5 & $8 \cdot 29$ & $<0.01$ \\
\hline
\end{tabular}

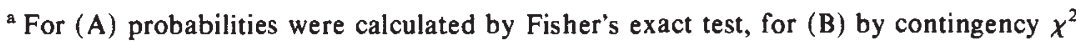
corrected for continuity.

$1972 a, b$; Semler, 1971; personal observation). While sampling in Nova Scotia we discovered a new species of Gasterosteus that often coexists with Apeltes and Pungitius. When first discovered this stickleback was thought to be a colour morph of $G$. aculeatus, with which it also coexists at many sites. However subsequent investigations (Hagen, Blouw and Armstrong, in preparation) show that it is reproductively isolated and that it differs from G. aculeatus in its adult size, breeding ecology, behaviour, and most strikingly, in male reproductive colour. The dorsal and lateral surfaces of breeding males are iridescent white instead of cryptic green. This colouration is highly reflective, so males are very conspicuous and easily visible at a distance. We call this fish the "white" stickleback.

Two aspects of the environments in which the white stickleback is found are relevant here. First, it breeds only in dense filamentous algae (Cladophora), providing abundant and effective cover from predators. Second, we caught few predatory fishes at such sites. Hence the white stickleback breeds only where predation risk is low, as is suggested by the brilliant colouration itself.

Since the white stickleback breeds where predation risk is low, we predict that spine number for both Apeltes and Pungitius is lower where they coexist with the white stickleback. A quantitative test is complicated by uncertainty concerning where the white stickleback is absent. The breeding season is brief and highly synchronous within colonies, and breeding time differs among sites. Thus absence of the white stickleback from a particular site at one time is an unreliable indicator of whether it breeds at that site. To minimise this difficulty the white stickleback was scored absent only at sites that were sampled repeatedly but where it was not found. Note this is not an independent test; the white stickleback breeds only in dense filamentous algae and spine number is known to be lower at sites with this vegetation (Blouw and Hagen, 1984b). Nevertheless the test is worthwhile because an unexplored dimension of environmental heterogeneity (presence of the white stickleback) is involved, so the test is on a unique subset of sites with filamentous algae. 
TABLE 4

Comparisons of Apeltes and Pungitius mean spine numbers among sites with and without the white stickleback by analysis of variance

\begin{tabular}{|c|c|c|c|c|c|c|c|c|}
\hline \multirow[b]{3}{*}{ Species } & \multicolumn{2}{|c|}{ Mean spine number } & \multirow{2}{*}{\multicolumn{6}{|c|}{ Analysis of variance }} \\
\hline & \multirow{2}{*}{$\begin{array}{l}\text { Whites } \\
\text { absent }\end{array}$} & \multirow{2}{*}{$\begin{array}{c}\text { Whites } \\
\text { present }\end{array}$} & & & & & & \\
\hline & & & Source & SS & d.f. & MS & F & $\mathbf{P}$ \\
\hline \multirow[t]{2}{*}{ Apeltes } & $4 \cdot 25$ & $4 \cdot 07$ & Among & 0.7302 & 1 & 0.7302 & $30 \cdot 8^{a}$ & $<0.001$ \\
\hline & $(\mathrm{N}=37)$ & $(\mathrm{N}=58)$ & Within & $2 \cdot 2052$ & 93 & 0.0237 & & \\
\hline \multirow[t]{2}{*}{ Pungitius } & 9.78 & $9 \cdot 27$ & Among & $1 \cdot 2570$ & 1 & $1 \cdot 2570$ & $20 \cdot 3$ & $<0.001$ \\
\hline & $(\mathrm{N}=13)$ & $(N=8)$ & Within & $1 \cdot 1758$ & 19 & 0.0619 & & \\
\hline
\end{tabular}

a Variances are unequal by Levene's test, but recalculation using both the Welch and Brown-Forsythe statistics (Brown and Forsythe, 1974a, b) confirm the conclusion at the same level of significance.

Mean spine numbers of Apeltes and Pungitius are significantly lower where the white stickleback is present (table 4). This is another example of the non-random distribution of spines with respect to environment, providing further evidence that the polymorphisms are subject to selection by predators.

The breeding colours of Pungitius males are also extreme where they coexist with the white stickleback. At most sites in our study area Pungitius males develop a darkly pigmented spot between the pelvic spines, the pelvics are white, and the body remains olive or brown with dark blotches as illustrated in McKenzie and Keenleyside (1970). But where they coexist with the white stickleback, Pungitius males are often entirely jet black and the pelvic spines are a glossy blue-white. Thus they too are conspicuous in these environments with reduced predation risk.

\section{Discussion}

The relationships among spine number, spine length, predators and vegetation are all parallel for Apeltes and Pungitius. This is strong evidence that selection is acting on the dorsal spines of both species. Since both species have more and longer spines where predators are present and where cover is reduced, and since predators are known to prey selectively on Apeltes (Blouw and Hagen, 1984c), the results are consistent with the hypothesis that predators are a common selective agent.

This conclusion demands a reinterpretation of McPhail's (1963) work on Pungitius. McPhail surveyed 132 samples for variation in four traits, including dorsal spine number and pelvic spine length, and hypothesised that present day patterns of variation in dorsal spines result from the dispersal of two forms of Pungitius that differentiated in separate glacial refugia during the Pleistocene era. $\mathrm{He}$ attributes local variation in the Maritime Provinces (and in some other areas) to gene flow between the two forms after post-glacial contact was re-established. The variation in pelvic spine length does not seem to parallel variation in dorsal spine number (but the method used to score spine length as a ratio of pectoral fin length seems questionable), and McPhail suggested that spine length 
differences among sites may be induced by combinations of salinity and temperature.

Since spine number in Pungitius is subject to selection, we suggest the variation among populations reflects spatial heterogeneity in selective forces rather than historical events of differentiation, dispersal and gene flow in relation to glaciation. The hypothesis of spatially varying selection is testable, it accounts for the covariation between Apeltes and Pungitius in both spine number and spine length, and it accounts for the correlation between spine number and spine length within each species. As well as resolving issues regarding the observed differentiation in Apeltes and Pungitius, tests of hypotheses of spatially varying selection will contribute much needed empirical evidence to recent models of evolution in heterogeneous environments (Felsenstein, 1976; Hedrick et al., 1976; Karlin, 1976, 1982; Powell and Taylor, 1979; Slatkin, 1978; Spieth, 1979), and to distinguishing between alternative hypotheses in biogeography (Endler, 1981, 1982a, b). If the geographic patterns produced by historical processes happen to coincide with present day geographical differences in selective regimes among sites, then the current patterns of variation may reflect historical events. Although we cannot disprove this, the likelihood of such coincidence seems small.

The correlation between the distribution of the white stickleback and spine number in Apeltes and Pungitius is also relevant in the context of evolution in heterogeneous environments because one component of environmental heterogeneity, filamentous algae, is identified as having a profound influence. The white stickleback breeds only in dense beds of filamentous alga (Cladophora), which provides exceptional cover from predators. And it is here that spine number for Apeltes and Pungitius is lower, spines are shorter, and the breeding colours of Pungitius are accentuated. It seems certain that the conspicuous colours of white Gasterosteus and black Pungitius males are for increased advertisement, and this may be explained by one or both of two hypotheses. First, sexual selection by female preference may favour enhancement of breeding colours in males (Endler, 1978, 1980, 1982c; Reznick and Endler, 1982; Semler, 1971) and the counterselection for crypsis exerted elsewhere by predators is reduced due to the abundant and effective cover. Second, males may be advertising to visually searching predators that they are unprofitable prey (Baker and Parker, 1979), unprofitable because of the excellent refuge provided by algae.

We are still left to explain why Apeltes and Pungitius have fewer and shorter spines at sites with dense filamentous algae. The three-spined morph is rare or absent throughout the range (Cox, 1923; Hildebrand and Schroeder, 1928; Krueger, 1961 ; Leim and Scott, 1966; Scott and Crossman, 1973), but in Denys Basin (Bras D'Or Lake, Nova Scotia) where there are few predators and abundant algae, it reaches remarkably high frequencies (Blouw and Hagen, 1984a). We have shown elsewhere (Blouw and Hagen, $1984 b$ ) that spine number in Apeltes is lower where it coexists with competitors, and we hypothesise that competition may select for lower spine number. Reimchen (1980) and Reist $(1980 a, b)$ suggest that invertebrate predators may be selective agents favouring reduced spines because many invertebrates grasp their prey, and spines may provide holdfasts. Thus it may be that reduced vulnerability to vertebrate predators at sites like those in Denys Basin allows increased response to competitors, invertebrate predators, or both. 
The search for patterns of covariation within and among species has proven highly productive in this study, and it should be applied more frequently among species of sticklebacks. The group is conspicuously variable for many traits, various combinations of species coexist (particularly on the east coast of North America), they occur in diverse environments, and they have similar ecologies. The method of interspecific covariation is efficient because it provides evidence for two or more species simultaneously. Furthermore, when combined with detailed sampling, measures of environmental variation, and patterns of correlation among traits within species, it has the advantage of limiting the number of potential selective agents because the hypothesised agents must be consistent with all aspects of the patterns of covariation within and among species. A search for patterns of covariation among species may also reveal unsuspected ecological differences among them. For example, the covariation between Apeltes and Pungitius breaks down at the two sites in Louisbourg Harbour, and this suggests they differ in some aspect of their ecology or behaviour there. The discordance is of particular interest because it occurs at an intrusion for high spine number in Apeltes. Investigating the reasons for the discordance may suggest explanations for the intrusions found elsewhere (Blouw and Hagen, 1984a).

Acknowledgements. We are grateful to G. Bennet, M. Biagi, and G. Armstrong for help with collections, and particularly to Guy Armstrong for help with scoring phenotypes. An anonymous reviewer provided valuable comments. Financial support was from NSERC grant A9547 to D.W.H. and a NSERC postdoctoral fellowship to D.M.B.

\section{REFERENCES}

BAKer, R. R. AND PARKer, G. A. 1979. The evolution of bird coloration. Proc. Roy. Soc. Lond. Ser. B., Vol. 287, 63-130.

Blouw, D. M. 1982. The Adaptive Significance of a Polymorphism for Dorsal Spine Number in Apeltes quadracus and Comparison with Several Coexisting Sticklebacks. Ph.D. thesis, University of New Brunswick.

BLOUW, D. M. AND HAGEN, D. W. 1981. Ecology of the fourspine stickleback, Apeltes quadracus, with respect to a polymorphism for dorsal spine number. Can. J. Zool., 59, 1677-1692.

BLOUW, D. M. AND HAGEN, D. W. 1984a. The adaptive significance of dorsal spine variation in the fourspine stickleback, Apeltes quadracus. I. Geographic variation in spine number. Can. J. Zool., (in press).

BLOUW, D. M. AND HAGEN, D. W. 1984b. The adaptive significance of dorsal spine variation in the fourspine stickleback, Apeltes quadracus. II. Phenotype-environment correlations. Can. J. Zool., (in press).

BLOUW, D. M. AND HAGEN, D. W. 1984c. The adaptive significance of dorsal spine variation in the fourspine stickleback, Apeltes quadracus. III. Correlated traits and experimental evidence on predation. Heredity, 53, 371-382.

BROWN, M. B. AND FORSYTHE, A. B. 1974a. Robust tests for the equality of variances. J. Amer. Stat. Assoc., 69, 364-367.

BROWN, M. B. AND FORSYTHE, A. B. 1974b. The small sample behaviour of some statistics which test the equality of several means. Technometrics, 16, 129-132.

CLARKE, B. 1975. The contribution of ecological genetics to evolutionary theory; detecting the direct effects of natural selection on particular polymorphic loci. Genetics, 79, 101-113.

Cox, P. 1923. Regional variation of the four-spined stickleback, Apeltes quadracus Mitchill. Can. Field-Nat., 37, 146-147.

ENDLER, J. A. 1978. A predator's view of animal color patterns. Evol. Biol. 11, 319-364.

ENDLER, J. A. 1980. Natural selection on color patterns in Poecilia reticulata. Evolution, 34, 76-91. 
ENDLER, J. A. 1981. Pleistocene forest refuges: fact or fancy? In Biological Diversification in the Tropics. G. Prance, (ed.) Columbia University Press, N.Y.

ENDLER, J. A. 1982a. Alternative hypotheses in biogeography: introduction and synopsis of the symposium. Amer. Zool, 22, 349-354.

ENDLER, J. A. 1982b. Problems in distinguishing historical from ecological factors in biogeography. Amer. Zool, 22, 441-452.

ENDLER, J. A. 1982c. Convergent and divergent effects of natural selection on color patterns in two fish faunas. Evolution, 36, 178-188.

FELSENSTEIN, J. 1976. The theoretical population genetics of variable selection and migration. Ann. Rev. Genet., 10., 253-280.

GILbertson, L. G. 1980. Variation and Natural Selection in an Alaskan Population of the Threespine Stickleback (Gasterosteus aculeatus L.) Ph.D. thesis, University of Washington, Seattle.

HAGEN, D. W. AND BLOUW, D. M. 1983. Heritability of dorsal spines in the fourspine stickleback (Apeltes quadracus). Heredity, 50, 275-281.

haGEN, D. W. AND MOODIE, G. E. E. 1979. Polymorphism for breeding colors in Gasterosteus aculeatus. I. Their genetics and geographic distribution. Evolution, 33, 641-648.

HAGEN, D. W., MOODIE, G. E. E. AND MOODIE, P. F. 1980. Polymorphism for breeding colors in Gasterosteus aculeatus. II. Reproductive success as a result of convergence for threat display. Evolution, 34, 1050-1059.

HEDRICK, P. W., GINEVAN, M. E. AND EWING, E. P. 1976. Genetic polymorphism in heterogeneous environments. Ann. Rev. Ecol. Syst., 7, 1-32.

HILDEBRAND. S. F. AND SHROEDER, W. C. 1928. Fishes of Chesapeake Bay. U.S. Bur. Fish. Bull., 43, Doc. 1024.

KARLIN, S. 1976. Population subdivision and selection-migration interactions. In Population Genetics and Ecology. S. Karlin and E. Nevo, (eds.) Academic Press, New York.

KARLIN, S. 1982. Classification of selection-migration structures and conditions for a protected polymorphism. In Evolutionary Biology, Vol. 14. M. K. Hecht, B. Wallace and G. T. Prance, (eds.) Plenum, New York.

KOEH N, R. K. AND MITTON, J. B. 1972. Population genetics of marine pelecypods. 1 Ecological heterogeneity and evolutionary strategy at an enzyme locus. Am. Nat., 106, 47-56.

KRUEGER, W. H. 1961. Meristic variation in the fourspine stickleback, Apeltes quadracus. Copeia, 1961, 442-450.

LEIM, A. H. AND SCOTT, W. B. 1966. Fishes of the Atlantic coast of Canada. Fish. Res. Board Can. Bull, 155.

MCKENZIE, J. A. AND KEENLEYSIDE, M. H. A. 1970. Reproductive behaviour of ninespine sticklebacks (Pungitius pungitius [L.]) in South Bay, Manitoulin Island, Ontario. Can. J. Zool., 48, 55-61.

MCPHAIL, J. D. 1963. Geographic variation in North American ninespine sticklebacks, Pungitius pungitius. J. Fish. Res. Bd. Canada, 20, 27-44.

MOODIE, G. E. E. 1972a. Morphology, life history, and ecology of an unusual stickleback (Gasterosteus aculeatus) in the Queen Charlotte Islands, Canada. Can. J. Zool., 50, 721-732.

MOODIE, G. E. E. 1972b. Predation, natural selection and adaptation in an unusual threespine stickleback. Heredity, 28, 155-167.

POWELL, J. R. AND TAYLOR, C. E. 1979. Genetic variation in ecologically diverse environments. Am. Sci., 67, 590-596.

REIMCHEN, T. E. 1980. Spine deficiency and polymorphism in a population of Gasterosteus aculeatus: an adaptation to predators? Can. J. Zool., 58, 1232-1244.

REIST, J. D. 1980a. Selective predation upon pelvic phenotypes of brook stickleback, Culaea inconstans, by northern pike, Esox lucius. Can. J. Zool., 58, 1245-1252.

REIST, J. D. $1980 \mathrm{~b}$. Predation upon pelvic phenotypes of brook stickleback, Culaea inconstans, by selected invertebrates. Can. J. Zool., 58, 1253-1258.

REZNICK, D. AND ENDLER, J. A. 1982. The impact of predation on life history evolution in Trinidadian guppies (Poecilia reticulata). Evolution, 36, 160-177.

SCOTT, w. B. AND CROSSMAN, E. J. 1973. Freshwater fishes of Canada. Fish. Res. Board Can. Bull, 184.

SEMLER, D. E. 1971. Some aspects of adaptation in a polymorphism for breeding colours in the threespine stickleback (Gasterosteus aculeatus L.). J. Zool. Lond., 165, 291-302.

SLATKIN, M. 1978. Spatial patterns in the distributions of polygenic characters. J. Theor. Biol., $70,213-228$.

SPIETH, P. T. 1979. Environmental heterogeneity: a problem of contradictory selection pressures, gene flow, and local polymorphism. Am. Nat., 113, 247-260. 
TURNER, J. R. G. 1977. Butterfly mimicry: the genetical evolution of an adaptation. In: Evolutionary Biology. Vol. 10, M. K. Hecht, W. C. Steere, and B. Wallace, (eds.). wootton, R. J. 1976. The Biology of the Sticklebacks. Academic Press, London. WORGAN, J. P. AND FITZGERALD, G. J. 1981. Habitat segregation in a salt marsh among adult sticklebacks (Gasterosteidae). Env. Biol. Fish., 6, 105-109.

ZAR, J. H. 1974. Biostatistical Analysis. Prentice-Hall Inc. Englewood Cliffs, New Jersey. 